\title{
Constraints on the three-dimensional thermal structure of the lower crust in the Japanese Islands
}

\author{
Ikuo Cho and Yasuto Kuwahara \\ Geological Survey of Japan, National Institute of Advanced Industrial Science and Technology, Tsukuba Central 7, Tsukuba 305-8567, Japan
}

(Received September 5, 2012; Revised January 22, 2013; Accepted January 28, 2013; Online published September 17, 2013)

\begin{abstract}
We propose a method for modeling a three-dimensional thermal structure with a particular focus on the lower crust. Our method enables high-resolution modeling without heat flow data, but with earthquake hypocenter data in the crust and seismic attenuation data in the upper mantle. In our method, the temperature at the bottom of the seismogenic layer is estimated under the assumption that the bottom depth corresponds to a brittle-ductile transition zone. Next, the temperature beneath the Moho discontinuity is estimated using seismic attenuation data of the mantle and a few point temperature data inferred from mantle xenoliths. Finally, the temperatures between the two depths are linearly interpolated. Attempts to construct an actual model for the Japanese Islands are also described.
\end{abstract}

Key words: Thermal structure, lower crust, modeling, numerical simulation, forecast.

\section{Introduction}

A strong three-dimensional nonuniformity is thought to exist in the thermal structure of the crust and the upper mantle beneath the Japanese Islands, where a cool oceanic plate is subducting while hot melts rise from the mantle (Nakajima and Hasegawa, 2009) (Fig. 1). The nonuniformity of the thermal structure in the deep crust affects the viscoelastic structure and, ultimately, has an influence on regional crustal deformations. For example, Shimamoto (1992) claimed that the three-dimensional viscoelastic crustal structure affects the distribution of active faults of the Japanese Islands. Iio et al. (2004) also suggested the possibility that the viscosity of the lower crust has a strong impact on the stress accumulation that causes inland earthquakes.

We intend to perform numerical simulations of crustal deformations of the Japanese Islands, based on a physical model, with a final goal of performing long-term (over several decades) forecasting of large inland earthquakes. For this purpose, it is required to model the three-dimensionally nonuniform viscoelastic (rheological) crustal structure on the basis of models of thermal and lithological structures, and to model the regional stress field to be applied as a boundary condition (Fig. 2). Fruitful results are not achievable without basic data on the deep crustal structure, with a maximum possible resolution. While the resolution needed for the earthquake forecasting is unknown, a minimum horizontal resolution of $30 \mathrm{~km}$ - a scale comparable to relatively large active faults in the Japanese Islands-is likely to be necessary to capture the horizontal scales over which stress regimes locally change. Once a viscoelastic-structure

Copyright (C) The Society of Geomagnetism and Earth, Planetary and Space Sciences (SGEPSS); The Seismological Society of Japan; The Volcanological Society of Japan; The Geodetic Society of Japan; The Japanese Society for Planetary Sciences; TERRAPUB.

doi: $10.5047 /$ eps.2013.01.005 model is constructed, a simulation can be executed, and then the results can be compared with observed data and fed back to the model until the requirements for resolution and accuracy can be assessed. If the accuracy of the simulations can be improved with this process, it may become possible to forecast, for example, the post-seismic crustal deformations after the 2011 Tohoku earthquake.

With the above as a background, this paper reports on the modeling of a three-dimensionally nonuniform thermal structure beneath the Japanese Islands focusing on the lower crust.

\section{Method}

\subsection{Defects of existing methods}

Typically, governing equations are solved to model a thermal structure in the deep crust by assuming factors such as the heat conductivity of rocks, the radioactive heat production, fluid convection, and partial melting, using heat flow data obtained at the ground surface (Jaupart and Mareschal, 2010). However, available heat flow data are not so dense. Although thermal gradient data in the inland areas of the Japanese Islands were considerably increased by Tanaka et al. (2004), they are still insufficient for our purpose, as described in Section 1, from the viewpoint that a statistical approach is required to analyze the data contaminated by shallow noises such as groundwater flow (e.g., Okubo et al., 2005) (Fig. 3). Further problems include bias due to frequent sampling from a hydrothermal field (Tanaka et al., 2004). Another problem is that the solidus temperature of the crustal materials depends on the chemical composition, pressure, and the quantity of $\mathrm{H}_{2} \mathrm{O}$ and $\mathrm{CO}_{2}$ (Ashworth and Brown, 1990), and cannot be definitely given. It was also revealed in recent years that the heat conductivity of crustal materials is much lower than previously thought under high-temperature conditions, and, hence, the crust may be partially melted owing to heat generation by crustal 


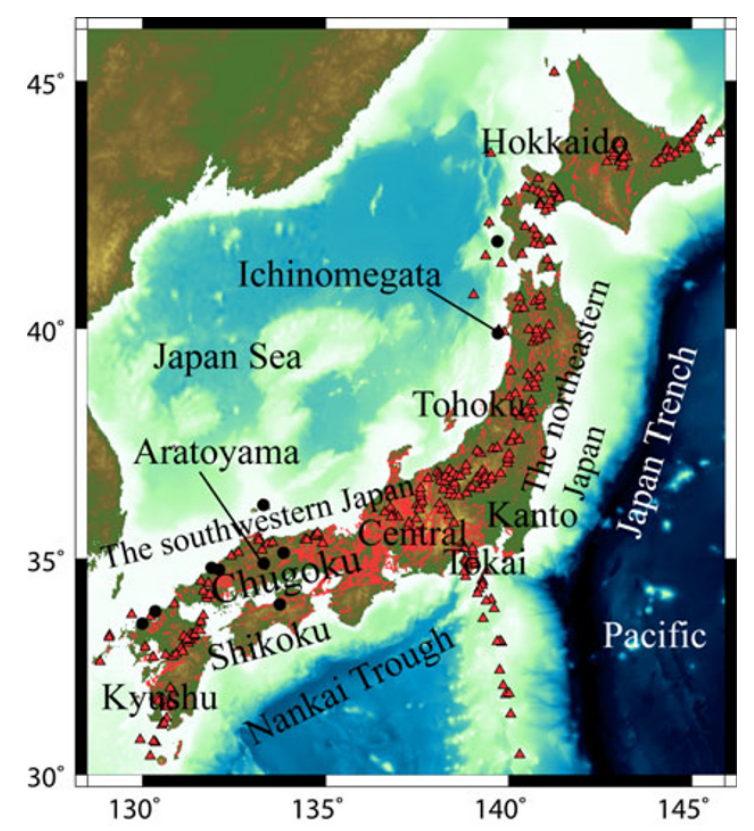

Fig. 1. Map showing the Japanese Islands. Red triangles and red traces indicate active volcanoes and active faults, respectively. Solid circles indicate the points at which mantle xenoliths were found (Arai et al., 2007). The Philippine Sea Plate subducts beneath the Japanese Islands toward west-northwest along the Nankai Trough.

deformations such as orogenic movements (Whittington et al., 2009).

Hasegawa et al. (2000) suggested another method to model the thermal structure of the crust: they estimated the thermal structure of the upper crust in the Tohoku district, Japan, from $P$-wave perturbations obtained by travel time tomography. It would be difficult, however, to apply their method to the lower crust because of the lack of information on the mineral distribution. Therefore, the problems in modeling the thermal structure of the deep crust are due to limitations in the information available on the distribution of material properties.

\subsection{A method proposed in this study}

We first estimate the temperature both immediately above and beneath the target depth of the lower crust, and then use the model under the assumption that the lower crust temperature is intermediate between those temperatures (Fig. 2). More specifically, the temperature at the bottom of the seismogenic layer is first estimated. Next, the temperature at a depth of more than $45 \mathrm{~km}$ (upper mantle) is inferred. Finally, temperatures between the two depth points are linearly interpolated at each latitude and longitude. A threedimensional thermal structure model is, thus, constructed all over the Japanese islands through this process. Meanwhile, in areas where the upper boundary of the Philippine Sea Plate (PSP) is at a depth of $45 \mathrm{~km}$ or less, we made use of existing research data to estimate the temperature distribution along the upper boundary of the PSP. Then, we linearly interpolate the temperatures in the regions between the upper boundary of the PSP and the bottom of the seismogenic layer. Temperatures at greater depths than the upper boundary of the PSP fall outside the realm of our research. Details for each step are described below.
2.2.1 The temperature of the bottom of the seismogenic layer According to Turcotte and Schubert (2002), the strength of rocks in a brittle region is a function of depth $z$ :

$$
\Delta \sigma_{b}=[ \pm 2 \mu(\rho g z-p)]\left[\left(1+\mu^{2}\right)^{1 / 2} \mp \mu\right]^{-1}
$$

where $\Delta \sigma_{b}$ is a tectonic deviatoric stress, $\mu$ is the friction coefficient, $\rho$ is density, $g$ is the gravitational acceleration, and $p$ is pore pressure. The upper and lower signs apply to reverse and normal faults, respectively. On the other hand, rocks flow at a depth deeper than the brittle-ductile transition (BDT) depth, and the flow strength $\Delta \sigma_{f}$ is expressed as the constitutive law of dislocation creep (e.g., Bürgmann and Dresen, 2008):

$$
\Delta \sigma_{f}=A^{-1 / n} f_{\mathrm{H}_{2} \mathrm{O}}^{-r / n} \dot{\varepsilon}^{1 / n} \exp [(Q+P V) /(n R T)],
$$

where $A$ is the material constant, $Q$ is the activation energy, $P$ is pressure, $V$ is the activation volume, and $n$ and $r$ are the stress and fugacity exponents, respectively, all of which are determined experimentally for each mineral. $\dot{\varepsilon}$ is the viscous strain rate, $f_{\mathrm{H}_{2} \mathrm{O}}$ is the fugacity of water, $R$ is the gas constant, and $T$ is the absolute temperature. At the depths where brittle to ductile transition occurs, the following equation holds:

$$
\Delta \sigma_{b}=\Delta \sigma_{f}
$$

Thus, the strength curve is described as the well-known 'Christmas-tree' model (Fig. 4).

A strong correlation is widely known to exist between the bottom depth of the seismogenic layer and the BDT depth (e.g., Sibson, 1982; Ito, 1990). This study sets appropriate values to the parameters other than the temperature $T$ at the bottom of the seismogenic layer for Eqs. (1) and (2), and solves for $T$ assuming that Eq. (3) holds at that depth.

This study uses D90 as the representative value for the bottom depth of the seismogenic layer, which is the depth at which more than $90 \%$ of earthquakes occur at a shallower depth (e.g., Tanaka, 2004). We obtained D90 through the following steps. First, we extracted all hypocenters (315,131 events), other than low-frequency events and artificial events, that occurred in the period from October 2001 to December 2008 from a unified hypocenter catalog of the Japan Meteorological Agency, with standard errors in the latitudinal and longitudinal directions within $0.05^{\circ}$, with standard errors in focal depth within $3 \mathrm{~km}$, and with magnitudes larger than 1 . Note that we did not exclude aftershock sequences of any earthquakes. Grid points were placed at $0.2^{\circ}$ latitudinal and longitudinal increments within the range of $124.7^{\circ} \mathrm{E}-147.1^{\circ} \mathrm{E}$ and $25.5^{\circ} \mathrm{N}-46.5^{\circ} \mathrm{N}$, enough to cover the target area depicted in Fig. 1. At each grid point, events were extracted in which the epicenters lie within a $10-\mathrm{km}$ radius from the grid point. Finally, the events were sorted in order of depth, and D90 was defined from the upper $90 \%$ of the events counting from the shallowest earthquake. Further, earthquake counts were limited to those having a depth shallower than $40 \mathrm{~km}$, or shallower than the Pacific plate and PSP, or shallower than the Moho discontinuity by Katsumata (2010). Some grid points were 


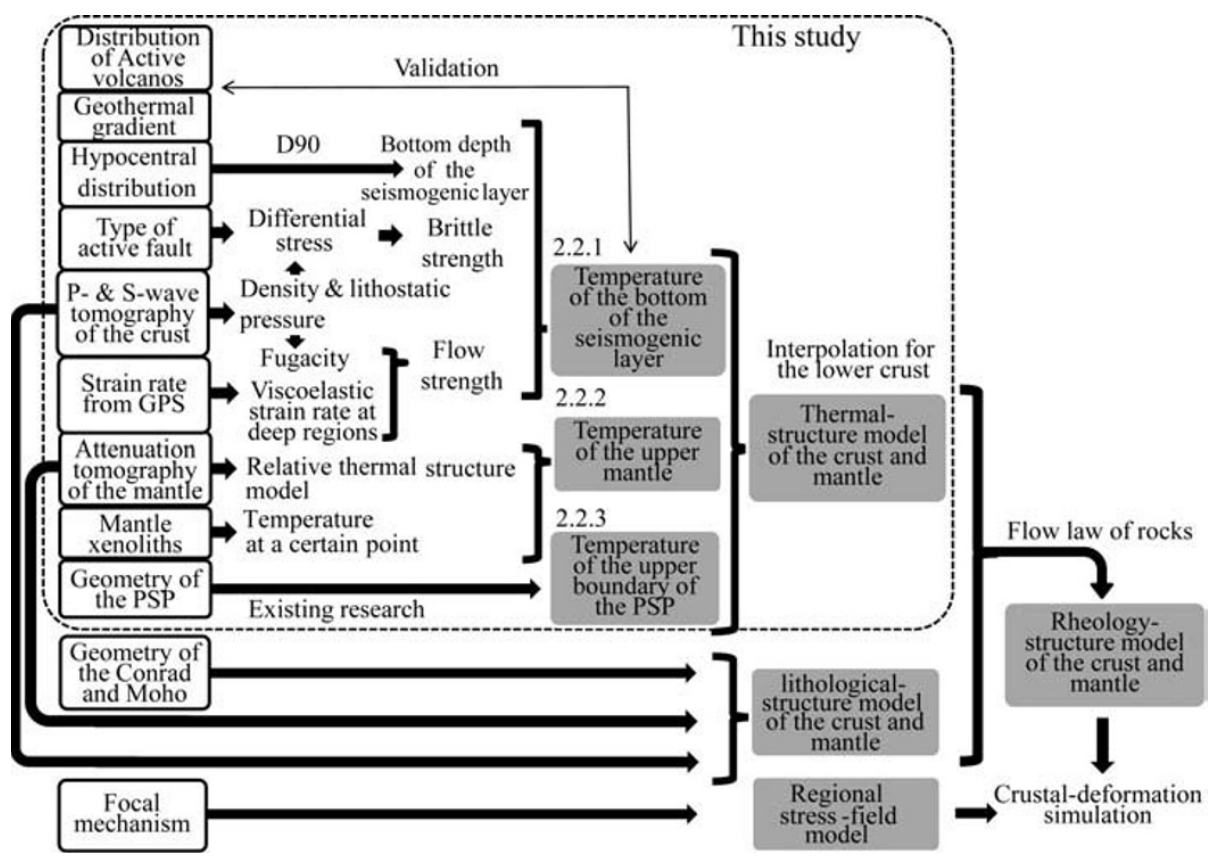

Fig. 2. Flow diagram to simulate the crustal deformation of the Japanese Islands. Numerals correspond to the section number in this study.

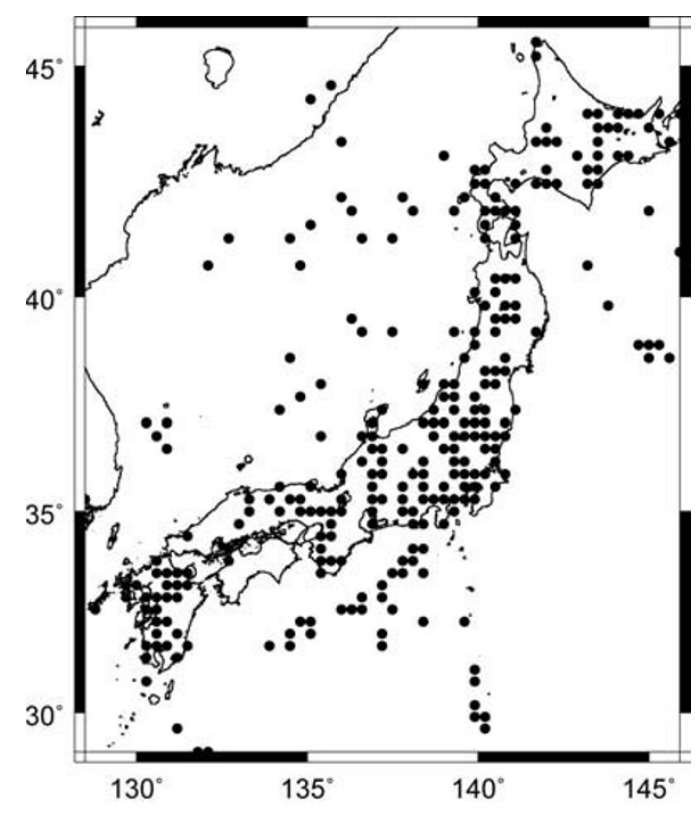

Fig. 3. Distribution of heat flow data. Solid circles indicate grid points at longitudinal and latitudinal intervals of $0.3^{\circ}$ having data points of three or more. The entire data of Tanaka et al. (2004), including those estimated by assuming the heat conductivity, were used for the compilation.

re-processed with a radius of $20 \mathrm{~km}$ whenever the number of events was less than ten. The distribution pattern of D90 obtained in this way (Fig. 5) is very similar to those of previous studies (e.g., Tanaka, 2004; Omuralieva et al., 2012).

Upon evaluating Eq. (1), the densities were calculated by converting the $P$-wave velocities (Matsubara et al., 2008) using an empirical relation by Christensen and Mooney (1995). The friction coefficient was set to 0.6 (Byerlee, 1978), and the pore pressure was calculated under the assumption of hydrostatic pressure. The fault type was set

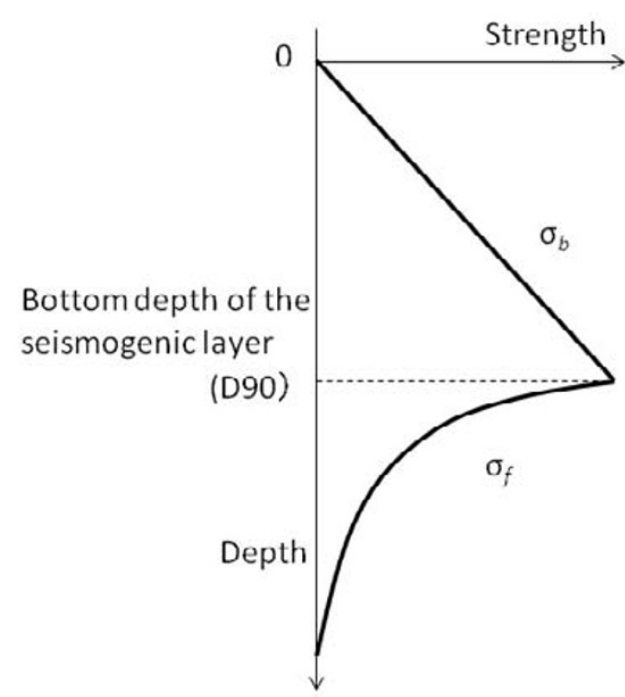

Fig. 4. Christmas-tree model of the depth distribution of the crustal strength.

to be reverse faults in northeastern Japan and Hokkaido, as strike-slip faults in southwestern Japan, and as normal faults in a part of Kyushu, according to the Earthquake Research Committee (2001). The value of the tectonic stress $\Delta \sigma_{b}$ for a strike-slip fault was set as the average of those for reverse and normal faults.

The horizontal strain rate in Eq. (2) was set using the analysis results of the Global-Positioning-System (GPS) data of Sagiya et al. (2000). Experimental results for quartz (Rutter and Brodie, 2004) were used for the parameters of Eq. (2) as the weakest mineral that composes granite. The fugacity of water was calculated by multiplying the lithostatic pressure by the fugacity coefficient of Holland and Powell (1998). Finally, Eq. (3) was solved for the unknown 


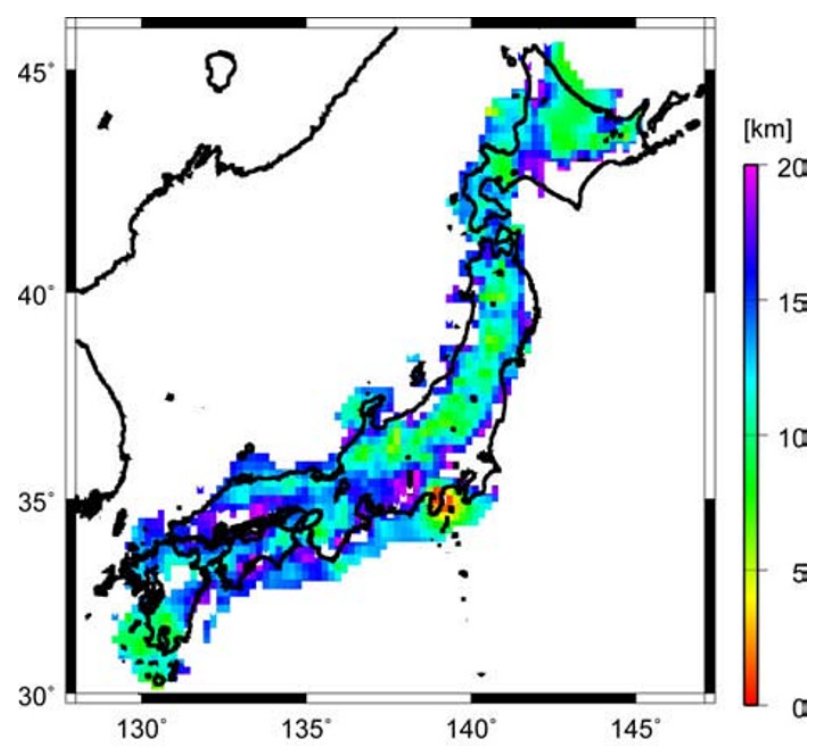

Fig. 5. Distribution of D90.

value $T$.

2.2.2 Thermal structure below $45 \mathrm{~km}$ The thermal structure at a depth of more than $45 \mathrm{~km}$ was modeled using the method reported by Nakajima and Hasegawa (2003). First, seismic attenuation tomography data of the mantle are converted to a three-dimensional, relative-thermal-structure model by using equation (16) of Karato (1998), in which the quality factor has a proportional relation to the exponential of the inverse of absolute temperature. Next, by taking into account the temperatures indicated by mantle xenoliths at a certain reference point, the relative-thermal-structure model is converted to an absolute-thermal-structure model.

For attenuation data, we used Nakamura (2009)'s result of the three-dimensional attenuation tomography of $S$ waves in the crust and the upper mantle across the Japanese Islands. The intervals between the grid points for tomography were $0.2^{\circ}$ both in the latitudinal and longitudinal directions, and a $30-\mathrm{km}$ interval was used for depth. Only the tomography data with sufficient resolution from a checkerboard test (Nakamura, 2009) were utilized in this study.

The points in which mantle xenoliths were found are located in the west of southwestern Japan and in the north of northeastern Japan (Fig. 1), and the equilibrium temperatures of the samples between those areas are known to be systematically different (Arai et al., 2007). We set Ichinomegata and Aratoyama as respective reference points for northeastern and southwestern Japan, and set the equilibrium temperatures to $950^{\circ} \mathrm{C}$ and $1050^{\circ} \mathrm{C}$, respectively, using the research result of Arai et al. (2007) as a reference. In most cases, the mantle xenoliths obtained in the Japanese Islands were spinel peridotite (Abe and Arai, 2005), which stably exists in the depth range shallower than about $60 \mathrm{~km}$ according to a $P-T$ diagram (e.g., Gill, 2010). Therefore, we set the representative depth, at which the mantle xenoliths in the Japanese Islands had existed, to $45 \mathrm{~km}$ as the intermediate depth between the Moho boundary (about 30 $\mathrm{km})$ and $60 \mathrm{~km}$.

Two absolute-thermal-structure models were thus created using the temperatures at the respective reference points, based on a relative-thermal structure model obtained using the attenuation tomography data of the mantle. These two models were integrated into a single model by taking a weighted average of the two models, and by gradually varying the weight of values in central Japan.

2.2.3 Temperature of the upper boundary of the Philippine Sea Plate (PSP) The temperature of the upper boundary of the PSP was given by assuming a thermal gradient for each region. According to Yoshioka and Murakami (2007), the temperature of the upper boundary of the PSP at a $30-\mathrm{km}$ depth, where it subducts along the Nankai Trough, ranges between 350 and $450^{\circ} \mathrm{C}$. Based on the fact that the maximum focal depths of small earthquakes in the Wadati-Benioff zone become significantly deeper in the Kyushu and Tokai-Kanto regions, Hasegawa et al. (2010) speculates that the thermal gradients are lower in these areas. Considering these previous studies, the thermal gradient on the upper boundary of the PSP was assumed to be $9^{\circ} \mathrm{C} / \mathrm{km}$ in $\mathrm{Kyushu}, 15^{\circ} \mathrm{C} / \mathrm{km}$ in Shikoku to central Japan, $11^{\circ} \mathrm{C} / \mathrm{km}$ in southern Kanto, and $7.5^{\circ} \mathrm{C} / \mathrm{km}$ in northern Kanto. A model by Nakajima and Hasegawa (2007), and Nakajima et al. (2009), was used for the depth of the upper boundary of the PSP.

\section{Results}

Figure 6(a) shows the distribution of the D90 temperature across the Japanese Islands, ranging between 320 and $420^{\circ} \mathrm{C}$. High-temperature areas corresponded closely with the distribution of active volcanoes (Fig. 1), and with the geothermal area in the northern part of central Japan.

In the thermal distribution at 45-km depth in Fig. 6(b), ranging between 800 and $1200^{\circ} \mathrm{C}$, the temperatures in northeastern Japan were generally lower than in southwestern Japan owing to differences in the reference temperature of the mantle xenoliths. Not shown here, the temperatures at the depths of the Conrad and Moho discontinuities (Katsumata, 2010) ranged between 400 and $700^{\circ} \mathrm{C}$ and between 600 and $900^{\circ} \mathrm{C}$, respectively.

The distribution of temperatures in the lower crust were such that, at a $24-\mathrm{km}$ depth for example, a high-temperature area at about $650^{\circ} \mathrm{C}$ was surrounded by a mid-temperature area at $500-600^{\circ} \mathrm{C}$, except in the southwestern area where PSP is subducting (Fig. 7). In southwestern Japan the temperatures around the subducting area are low, ranging between 250 and $350^{\circ} \mathrm{C}$, but the rest of the inland area reflects the thermal distribution of the upper mantle, and the temperature tends to be higher than in northeastern Japan.

\section{Discussion and Concluding Remarks}

The model obtained in this study is consistent with previous studies. For example, Hasegawa et al. (2000) compared the spatial changes in the isothermal line at $300^{\circ} \mathrm{C}$, $400^{\circ} \mathrm{C}$, and $500^{\circ} \mathrm{C}$, from $P$-wave perturbations and the cutoff depth of shallow seismicity, and showed that the cut-off depth generally matches the isothermal line at $400^{\circ} \mathrm{C}$. Strict comparisons are difficult because their "cut-off depth" is not clearly defined, but their result does not contradict our model of the thermal distribution for D90 which has an average value of $385^{\circ} \mathrm{C}$ with a standard deviation of $24^{\circ} \mathrm{C}$. 
(a) Temperature at depth of D90

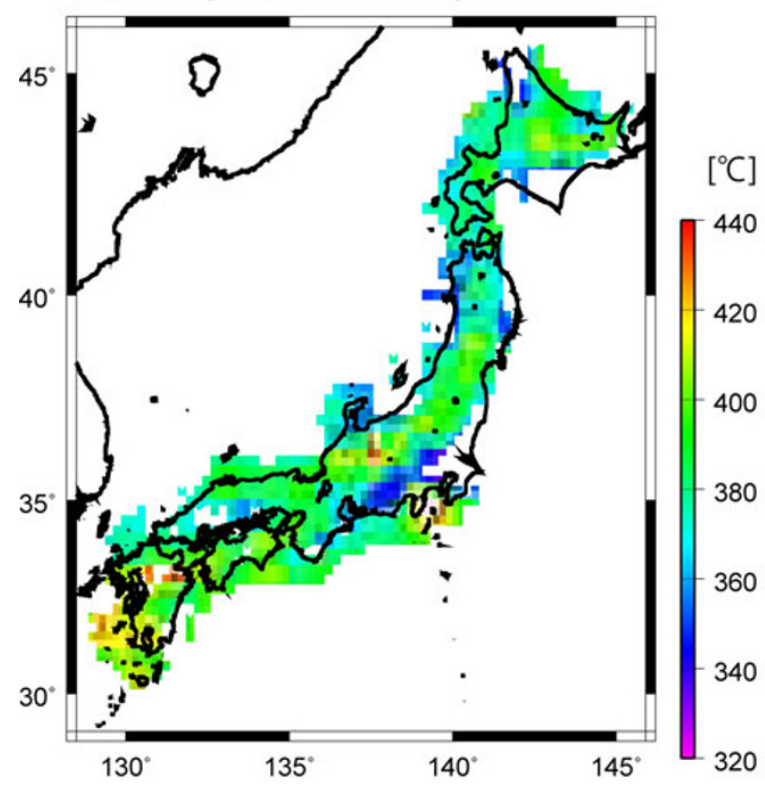

(b) Temperature at 45-km depth

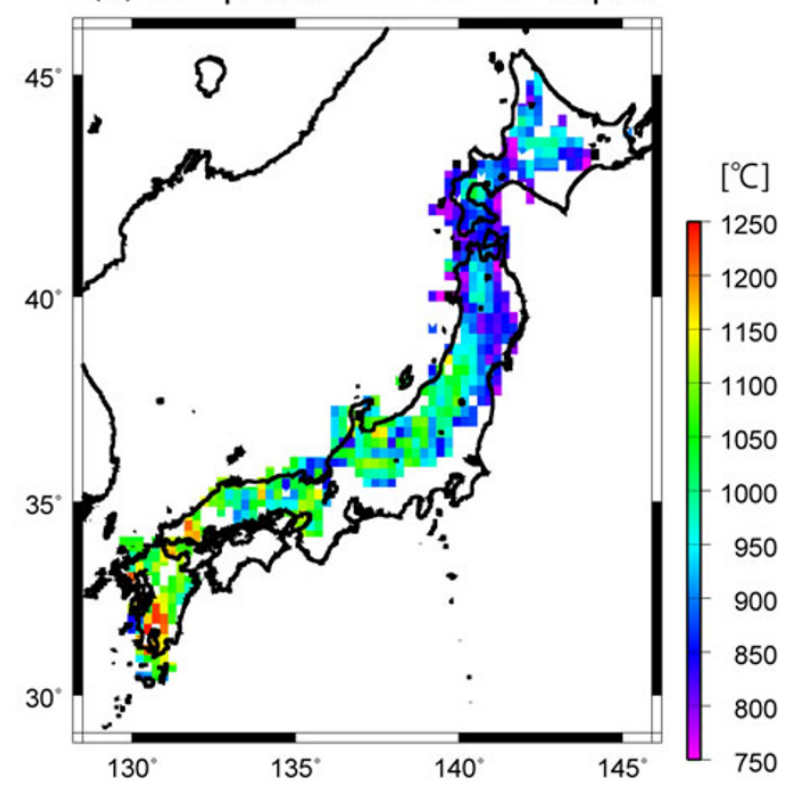

Fig. 6. Temperature distribution at the depth of D90 (a) and 45-km depth (b).

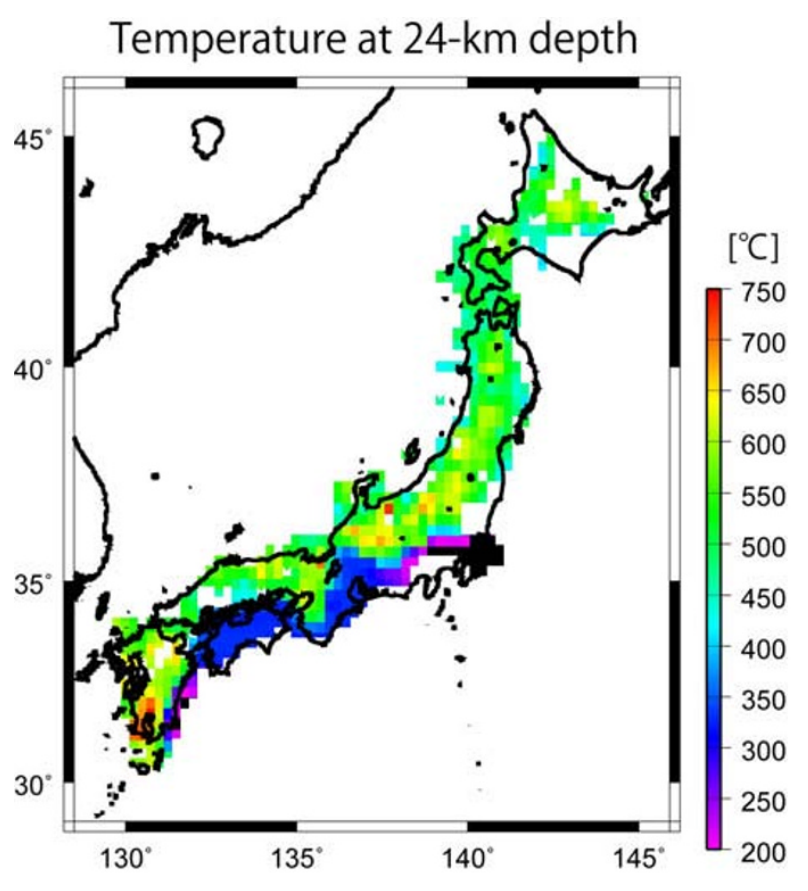

Fig. 7. Temperature distribution at 24-km depth.

Also, Tanaka (2004) estimated that the temperature at D90 in the Japanese Islands ranges between $250^{\circ} \mathrm{C}$ and $450^{\circ} \mathrm{C}$ on the basis of the thermal gradient data. In addition, our model corresponds well with the thermal distribution that is collaterally calculated in the simulation of the transportation of fluid within the crust and mantle (Iwamori, 2007).

We calculated the geothermal gradients between the surface and D90 using the geothermal structure model obtained in this study, assuming the temperature at the surface to be $0^{\circ} \mathrm{C}$. The geothermal gradients thus obtained were mostly distributed in the range of $20-40^{\circ} \mathrm{C} / \mathrm{km}$ (Fig. 8), the distri- bution pattern of which closely matches the measured data of Tanaka et al. (2004), although the present result is generally lower than the measured values. This discrepancy may come from (i) the fact that Tanaka et al. (2004)'s data contain a number of points from the hydrothermal field, (ii) the difference between the depth ranges used for the calculation of the geothermal gradient, and/or (iii) the possible underestimation of the D90 temperature of our model in the hydrothermal regions. The D90 temperature of our model becomes higher if the friction coefficient $\mu$ is set to a value smaller than 0.6. For example, the D90 temperature at $10-\mathrm{km}$ depth is $374^{\circ} \mathrm{C}$ when $\mu$ is set to 0.6 and the other parameters $\left(\rho, f_{\mathrm{H}_{2} \mathrm{O}}, \dot{\varepsilon}\right)$ to $\left(2.8 \mathrm{~g} / \mathrm{m}^{3}, 65 \mathrm{MPa}, 10^{-15}\right.$ strain/s), while it becomes $400^{\circ} \mathrm{C}$ when $\mu$ is set to 0.4 . Furthermore, even if $\mu$ is fixed to 0.6 , if the pore pressure is abnormally high such as $50 \%$ and $80 \%$ of the lithostatic pressure, the temperature can still take higher values of $385^{\circ} \mathrm{C}$ and $429^{\circ} \mathrm{C}$, respectively.

We assumed D90 as the representative depth of BDT for simplicity. It should be noted, however, that more recent studies have suggested that the zone over which earthquakes may nucleate is actually a subset of the range over which brittle deformation occurs, with the seismogenic zone having a velocity-weakening frictional property (e.g., Scholz, 1998). Therefore, D90 possibly represents the depth at which velocity-strengthening starts to dominate, and the BDT lies in the deeper regions. In that case, our assumption that D90 coincides with the BDT may underestimate the depth of the BDT. But, on the other hand, it is speculated that the frictional-stability transition and the BDT are closely related to each other (e.g., Scholz, 2002), and, in fact, there is an observation that co-seismic frictional slip and aseismic plastic flaw coexist at the bottom of the seismogenic zone (e.g., Takagi et al., 2000). To further complicate matters, the BDT may not represent a sharp transition from brittle to ductile behavior, but rather a more gradual 
(a) This study

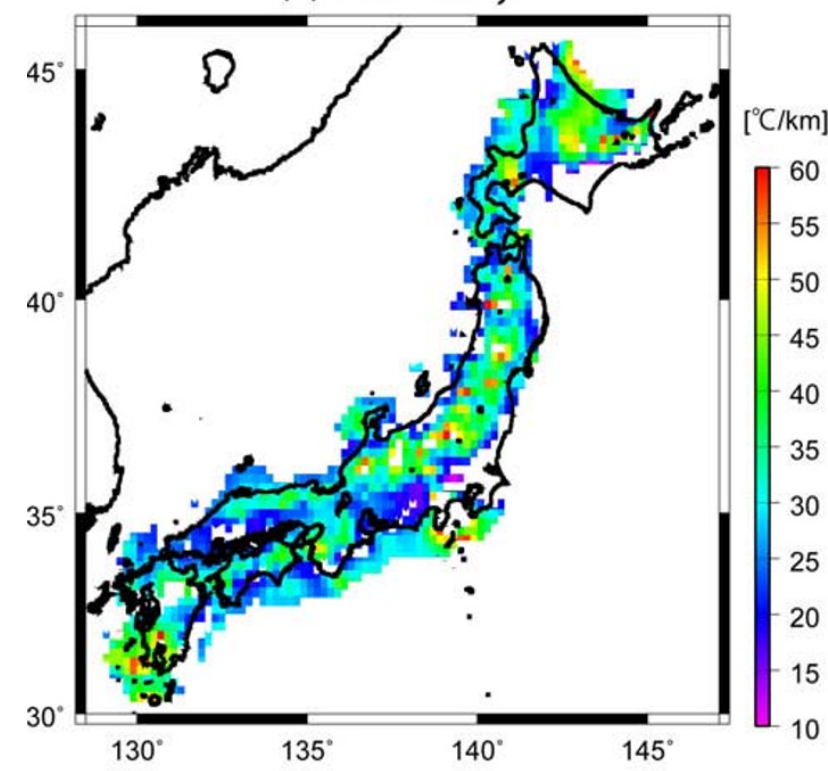

(b) Tanaka et al. (2004)

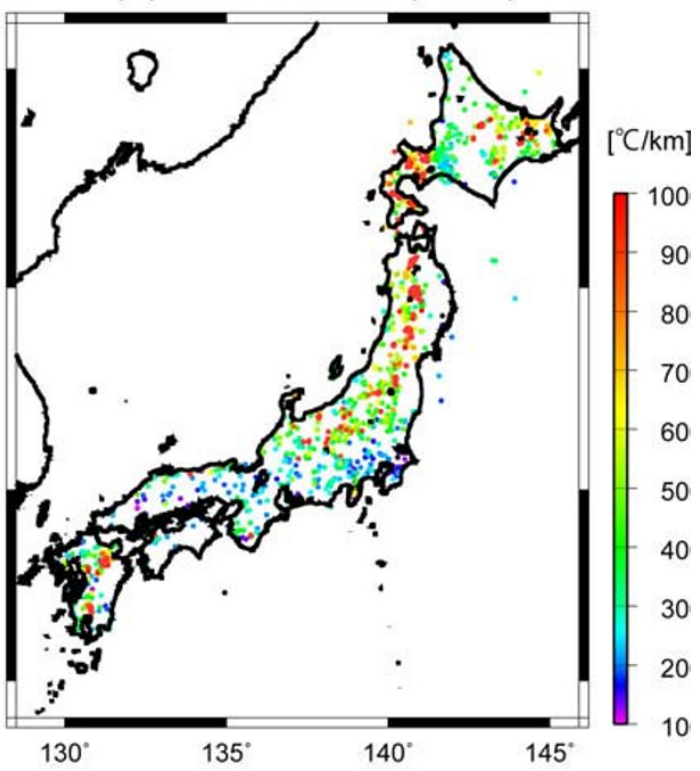

Fig. 8. Geothermal gradient. The left panel (a) indicates geothermal gradients between the ground surface and the D90 depth obtained in this study. The right panel (b) indicates geothermal gradients measured at boreholes (Tanaka et al., 2004), the depth of which ranges from 300 and $6400 \mathrm{~m}$ and averages $1100 \mathrm{~m}$.

zone of semi-brittle-behavior (e.g., Kohlstedt et al., 1995). Given the lack of constraints on the frictional-stability and BDT, we retain the simplest assumption that D90 represents the BDT depth. Further refinement of this model may be possible with better information about the transitional properties at the bottom of the seismogenic zone in the future.

It is expected from Eqs. (1)-(3) that the BDT temperature becomes lower as the BDT depth becomes deeper. For example, while we can calculate the BDT temperature at 10$\mathrm{km}$ depth as $374^{\circ} \mathrm{C}$ assuming $\mu$ is 0.6 and $p$ the hydrostatic pressure, the temperature becomes $358^{\circ} \mathrm{C}$ when the depth is set to $15 \mathrm{~km}$. In fact, a strong correlation was found between the temperature and the logarithmic depth of D90 of our model, with a correlation coefficient of -0.85 . By comparison, the correlation coefficient between the temperature and the logarithmic strain rate was 0.44 , much lower than that for D90.

It should be noted that the following problems arise upon using the GPS data as the strain rate for Eq. (2): (i) $\dot{\varepsilon}$ in Eq. (2) represents the viscous strain rate, but the GPS data are also affected by the elastic strain rate that cyclically accumulate during interplate earthquakes with a recurrence time interval about 100 years; (ii) differential stress that generates reverse and normal faults is the absolute value of the difference between principal stresses in the horizontal and vertical directions (Anderson's Law), but GPS data analyses lean towards the evaluation of plane strain rate using horizontal components only. The vertical component has been recognized to have a poorer quality and has seldom been subjected to detailed examinations. This is true also for data provided by Sagiya et al. (2000), which we utilized in this study. Therefore, we used the horizontal maximum shear strain rate as the representative scalar data.

The heat flow data, used in the conventional method to model a thermal structure on the basis of a partial differ- ential equation, are obtainable only at the ground surface, which is generally more than $10 \mathrm{~km}$ above the lower crust. Heat flow data are also much sparser than the hypocenter distribution data (Fig. 3). Furthermore, one should accurately know the mineral distribution and the environment in the lower crust to solve the partial differential equation. Therefore, our method can be expected to have a higher resolution and to be more robust than the conventional method to model the thermal structure of the lower crust for forecasting simulations of crustal deformations, despite the aforementioned flaws. The applicability of our method is owed to the high seismicity beneath Japan. Thus, our method is possibly applicable to regions other than Japan if they have high seismicity. We are planning to validate the usability of our method by constructing a viscoelastic crustal structure model beneath Japan and executing a crustal deformation simulation, based on the thermal structure model obtained in this study.

Acknowledgments. Data on the seismic attenuation tomography were provided by Dr. Ryoichi Nakamura. Data on the Philippine Sea Plate depth were provided by Dr. Junichi Nakajima. Data on the Conrad and Moho discontinuity depths were provided by Dr. Akio Katsumata. Constructive comments by Dr. Susan Ellis and an anonymous reviewer significantly improved the manuscript. Data on hypocenters, used to determine D90, was processed through a joint effort between the Japan Meteorological Agency and the Ministry of Education, Culture, Sports, Science and Technology.

\section{References}

Abe, N. and S. Arai, Petrography and geochemistry of the mantle xenoliths: Implications for lithospheric mantle beneath the Japan arcs, $J$. Petrol. Mineral. Sci., 34, 143-158, 2005 (in Japanese with English abstract).

Arai, S., N. Abe, and S. Ishimaru, Mantle peridotites from the Western Pacific, Gondwana Res., 11, 180-1991, doi:10.1016/j.gr.2006.04.004, 2007. 
Ashworth, J. R. and M. Brown, An overview of diverse responses to diverse processes at high crustal temperatures, in High-temperature Metamorphism and Crustal Anatexis, The Mineralogical Society Series 2, edited by J. R. Ashworth and M. Brown, pp. 1-18, Kluwer Academic, London, 1990.

Bürgmann, R. and G. Dresen, Rheology of the lower crust and upper mantle: Evidence from rock mechanics, geodesy, and field observations, Ann. Rev. Earth Planet. Sci., 36, 531-67, doi:10.1146/annurev.earth.36.031207.124326, 2008.

Byerlee, J. D., Friction of rocks, Pure Appl. Geophys., 116, 615-626, 1978.

Christensen, N. I. and W. D. Mooney, Seismic velocity structure and composition of the continental crust: A global view, J. Geophys. Res., 100, S9761-9788, 1995.

Earthquake Research Committee, On the method to evaluate long-term probabilities of earthquake occurrence, Headquarters for Earthquake Research Promotion, Tokyo, 2001 (in Japanese).

Gill, R., Igneous Rocks and Processes: A Practical Guide, John Wiley \& Sons, 2010.

Hasegawa, A., A. Yamamoto, N. Umino, S. Miura, S. Horiuchi, D. Zhao, and H. Sato, Seismic activity and deformation process of the overriding plate in the northeastern Japan subduction zone, Tectonophysics, 319, 225-239, 2000.

Hasegawa, A., J. Nakajima, N. Uchida, F. Hirose, S. Kita, and T. Matsuzawa, Slab structure beneath the Japanese Islands and earthquake generation, J. Geogr., 119, 190-204, 2010 (in Japanese with English abstract).

Holland, T. J. B. and R. Powell, An internally-consistent thermodynamic dataset for phases of petrological interest, J. Metamorphic Geol., 16, 309-343, 1998.

Iio, Y., T. Sagiya, and Y. Kobayashi, What controls the occurrence of shallow intraplate earthquakes?, Earth Planets Space, 56, 1077-1086, 2004.

Ito, K., Regional variations of the cutoff depth of seismicity in the crust and their relation to heat flow and large inland earthquakes, J. Phys. Earth, 38, 223-250, 1990

Iwamori, H., Transportation of $\mathrm{H}_{2} \mathrm{O}$ beneath the Japan arcs and its implications for global water circulation, Chem. Geol., 239, 182-198, doi:10.1016/j.chemgeo.2006.08.011, 2007.

Jaupart, C. and J.-C. Mareschal, Heat Generation and Transport in the Earth, Cambridge University Press, 2010.

Karato, S., A dislocation model of seismic wave attenuation and microcreep in the Earth: Harold Jeffreys and the rheology of the solid Earth, Pure Appl. Geophys., 153, 239-256, 1998.

Katsumata, A., Depth of the Moho discontinuity beneath the Japanese Islands estimated by traveltime analysis, J. Geophys. Res., 115, B04303, doi:10.1029/2008JB005864, 2010.

Kohlstedt, D. L., B. Evans, and S. J. Mackwell, Strength of the lithosphere: Constraints imposed by laboratory experiments, J. Geophys. Res., 100, 17587-17602, 1995.

Matsubara, M., K. Obara, and K. Kasahara, Three-dimensional P- and Svelocity structures beneath the Japan Islands obtained by high-density seismic stations by seismic tomography, Tectonophysics, 454, 86-103, doi:10.1016/j.tecto.2008.04.016, 2008.

Nakajima, J. and A. Hasegawa, Estimation of thermal structure in the mantle wedge of northeastern Japan from seismic attenuation data, Geophys. Res. Lett., 30, 1760, doi:10.1029/2003GL017185, 2003.

Nakajima, J. and A. Hasegawa, Subduction of the Philippine Sea plate beneath southwestern Japan: Slab geometry and its re- lationship to arc magmatism, J. Geophys. Res., 112, B08306, doi:10.1029/2006JB004770, 2007.

Nakajima, J. and A. Hasegawa, Seismic evidence for thermally-controlled dehydration reaction in subducting oceanic crust, Geophys. Res. Lett., 36, L03303, doi:10.1029/2008GL036865, 2009.

Nakajima, J., F. Hirose, and A. Hasegawa, Seismotectonics beneath the Tokyo metropolitan area, Japan: Effect of slab-slab contact and overlap on seismicity, J. Geophys. Res., 114, B08309, doi:10.1029/2008JB006101, 2009.

Nakamura, R., 3-D attenuation structure beneath the Japanese islands, source parameters and site amplification by simultaneous inversion using short period strong motion records and predicting strong ground motion, PhD Thesis, Tokyo University, Japan, 2009.

Okubo, Y., Y. Uchida, M. Taniguchi, A. Miyakoshi, and J. Safanda, Statistical analysis for thermal data in the Japanese Islands, Phys. Earth Planet. Inter., 152, 277-291, doi:10.1016/j.pepi.2005.04.013, 2005.

Omuralieva, A. M., A. Hasegawa, T. Matsuzawa, J. Nakajima, and T. Okada, Lateral variation of the cutoff depth of shallow earthquakes beneath the Japan Islands and its implications for seismogenesis, Tectonophysics, 518, 93-105, 2012.

Rutter, E. H. and K. H. Brodie, Experimental intracrystalline plastic flow in hot-pressed synthetic quartzite prepared from Brazilian quartz crystals, J. Struct. Geol., 26, 259-270, doi:10.1016/j.jsg.2004.04.006, 2004.

Sagiya, T., S. Miyazaki, and T. Tada, Continuous GPS array and presentday crustal deformation of Japan, Pure Appl. Geophys., 157, 23032322, 2000.

Scholz, C. H., Earthquakes and friction laws, Nature, 391, 37-42, 1998.

Scholz, C. H., The Mechanics of Earthquake and Faulting, Cambridge University Press, 2002.

Shimamoto, T., Rheology of rocks and plate tectonics, in Comprehensive Rock Engineering, vol. 1, Fundamentals, edited by E. T. Brown, pp. 93 108, Pergamon Press, Oxford, 1992.

Sibson, R. H., Fault zone models, heat flow, and the depth distribution of earthquakes in the continental crust of the United States, Bull. Seismol. Soc. Am., 72, 151-163, 1982.

Takagi, H., K. Goto, and N. Shigematsu, Ultramylonite bands derived from cataclasite and pseudotachylyte in granites, northeast Japan, J. Struct. Geol., 22, 1325-1339, 2000.

Tanaka, A., Geothermal gradient and heat flow data in and around Japan (II): Crustal thermal structure and its relationship to seismogenic layer, Earth Planets Space, 56, 1195-1199, 2004.

Tanaka, A., M. Yamano, Y. Yano, and M. Sasada, Geothermal gradient and heat flow data in and around Japan (I): Appraisal of heat flow from geothermal gradient data, Earth Planets Space, 56, 1191-1194, 2004.

Turcotte, D. L. and G. Schubert, Geodynamics, 2nd ed., Cambridge University Press, 2002.

Whittington, A. G., A. M. Hofmeister, and P. I. Nabelek, Temperaturedependent thermal diffusivity of the Earth's crust and implications for magmatism, Nature, 458, doi:10.1038/nature07818, 2009.

Yoshioka, S. and K. Murakami, Temperature distribution of the upper surface of the subducted Philippine Sea Plate along the Nankai Trough, southwest Japan, from a three-dimensional subduction model: Relation to large interplate and low-frequency earthquakes, Geophys. J. Int., 171, 302-315, doi:10.1111/j.1365-246X.2007.03510.x, 2007.

I. Cho (e-mail: ikuo-chou@aist.go.jp) and Y. Kuwahara 